\title{
Qualidade fisiológica de sementes das pimentas malagueta e biquinho durante a ontogênese
}

\author{
Haynna Fernandes Abud(1), Eduardo Fontes Araujo(1), Roberto Fontes Araujo(2), Alisson Vinicius Araujo(1) \\ e Cleide Maria Ferreira Pinto(2)
}

\begin{abstract}
(1)Universidade Federal de Viçosa (UFV), Centro de Ciências Agrárias, Departamento de Fitotecnia, Avenida P.H. Rolfs, s/no, Centro, CEP 36570-000 Viçosa, MG, Brasil. E-mail: hfabud@gmail.com, efaraujo@ufv.br, viniciusnca@yahoo.com.br (2)Empresa de Pesquisa Agropecuária de Minas Gerais, Campus UFV, Caixa Postal 216, CEP 36570-000 Viçosa, MG, Brasil. E-mail: rfaraujo@ufv.br, cleide.pinto@epamig.ufv.br
\end{abstract}

Resumo - O objetivo deste trabalho foi avaliar alterações fisiológicas durante a ontogênese de sementes das pimentas malagueta e biquinho, e determinar o melhor estádio para colheita. As flores em antese foram etiquetadas diariamente e os frutos foram colhidos aos 25, 40, 55, 70, 85 e 100 dias após a antese (DAA). Em cada época de maturação, as sementes foram avaliadas quanto a: teor de água, massa de matéria seca, germinação, primeira contagem de germinação, índice de velocidade de germinação e envelhecimento acelerado. O início do desenvolvimento das sementes foi caracterizado pelo acúmulo de matéria seca, e ocorreu até os 80 DAA, para pimenta malagueta, ou até os 70 DAA, para pimenta biquinho. Em sementes ortodoxas, como as da pimenteira, observa-se decréscimo no teor de água após elas atingirem máxima matéria seca. Aos 100 DAA, o teor de água foi de $14 \%$, na pimenta malagueta, e de $15 \%$, na pimenta biquinho. As sementes colhidas aos 25 e 40 DAA não germinaram. A percentagem de germinação aumentou entre os 40 e 70 DAA, e diminuiu a partir de então. A maturidade fisiológica das sementes de pimentas malagueta e biquinho ocorre aproximadamente aos 70 DAA, época ideal para colheita.

Termos para indexação: Capsicum, envelhecimento acelerado, germinação, maturação, potencial fisiológico, vigor.

\section{Physiological quality of "malagueta" and "biquinho" pepper seeds during ontogeny}

\begin{abstract}
The objective of this work to evaluate the physiological changes during seed ontogeny of "malagueta" and "biquinho" pepper, and to determine the best stage for harvest. Flowers in anthesis were tagged daily, and fruits were collected at 25, 40, 55, 70, 85, and 100 days after anthesis (DAA). In each maturation time, seeds were evaluated for water content, dry weight, germination, first germination count, germination speed index, and accelerated aging. The beginning of seed development was characterized by dry matter accumulation, which occurred until 80 DAA for "malagueta" pepper and 70 DAA for "biquinho" pepper. In orthodox seeds, such as pepper, after reaching maximum dry matter, a decrease is observed in water content. At 100 DAA, water content was $14 \%$ for "malagueta" pepper and $15 \%$ for "biquinho" pepper. Seeds harvested at 25 and 40 DAA did not germinate. Germination percentage increased between 40 and 70 DAA, and decreased thereafter. Physiological maturity of "malagueta" and "biquinho" peppers occurs at approximately 70 DAA, which is the ideal time for harvest.
\end{abstract}

Index terms: Capsicum, accelerated aging, germination, maturation, physiologic potential, vigor.

\section{Introdução}

O desenvolvimento das sementes é caracterizado por uma série de alterações físicas, morfológicas, fisiológicas e bioquímicas, que ocorrem a partir da fecundação do óvulo e continuam até se atingir a maturidade fisiológica (Vidigal et al., 2006; Berger et al., 2008; Hehenberger et al., 2012). A maturação de sementes de angiospermas é um processo complexo que consiste no crescimento e no desenvolvimento coordenado do tegumento, do endosperma e do embrião (Kesavan et al., 2013) em estruturas distintas, porém justapostas (Ingram, 2010).

A formação das sementes pode ser dividida em duas fases: a inicial, caracterizada pelo pré-armazenamento, e a segunda, ou fase de transição, caracterizada pelo 
acúmulo de reservas (Weber et al., 2010). No entanto, de acordo com Castro et al. (2004), o desenvolvimento da maioria das sementes pode ser divido em três fases confluentes: crescimento inicial do embrião (embriogênese); acúmulo de reservas, com a síntese de compostos como amido, proteínas e lipídeos (fase intermediária de maturação); e desidratação das sementes (término do desenvolvimento).

Segundo Bewley et al. (2013), na fase de acúmulo de reservas, o embrião apresenta elevado potencial germinativo. Durante a maturação das sementes são iniciados mecanismos de proteção, para preservar a integridade dos componentes celulares, quando a água for removida durante a secagem (Bewley et al., 2013). Além disso, os compostos de reserva permanecem intactos nessa fase (Graham, 2008). No término do desenvolvimento, as sementes entram em estado de repouso, o que permite sua sobrevivência em diferentes condições ambientais (Gutierrez et al., 2007; Leprince \& Buitink, 2010). Em sementes ortodoxas, o processo de maturação é encerrado com uma fase pré-programada de dessecação (Angelovici et al., 2010).

Pesquisas relacionadas à maturação das sementes são imprescindíveis para o planejamento e a definição do momento ideal de colheita, assim que a máxima qualidade seja alcançada em campo. Estudos para determinação do estádio ideal de colheita em espécies de frutos carnosos foram relatados para: mamão (Carica papaya L.) por Tokuhisa et al. (2008), tomate (Lycopersicon esculentum Mill.) por Vidigal et al. (2006) e Dias et al. (2006a, 2006b), pimenta cultivar Amarela comprida (Capsicum annuum L.) por Vidigal et al. (2009a, 2009b, 2011), pimenta habanero (C. chinense Jacq.) por Queiroz et al. (2011) e berinjela (Solanum melongena L.) por Martins et al. (2012).

A pimenta é uma planta que apresenta crescimento indeterminado, com florescimento e frutificação contínuos (Vidigal et al., 2009b), o que resulta em completa desuniformidade de desenvolvimento de frutos e sementes. Assim, em uma mesma planta, são encontrados frutos em diversos estádios de maturação. Essa característica dificulta a determinação da época de maturidade fisiológica das sementes e, consequentemente, o momento ideal de colheita dos frutos para obtenção de sementes com alta qualidade fisiológica (Vidigal et al., 2009b).

A colheita no momento ideal favorece a preservação do potencial fisiológico das sementes, por evitar a deterioração que ocorreria caso estas fossem mantidas no campo após a maturidade fisiológica. Além disso, colheitas precoces, fora do momento ideal, aumentam a quantidade de sementes imaturas no lote (Vidigal et al., 2009b).

O termo maturidade fisiológica é definido por Ellis \& Pieta Filho (1992) como o ponto de máxima qualidade fisiológica das sementes. Entretanto, para Weber et al. (2010), o ponto de maturidade fisiológica é observado quando as sementes atingem o máximo de acúmulo de matéria seca e o mais alto nível de diferenciação, antes que se inicie o processo de secagem das sementes.

Para definir o acúmulo máximo de matéria seca, Ellis \& Pieta Filho (1992) sugeriram o termo "maturidade de massa”, que não teria relação com a máxima qualidade fisiológica, que pode ocorrer um pouco antes ou depois da maturidade de massa. Em pimenta (Vidigal et al., 2009a, 2009b), pimentão (Demir \& Ellis, 1992b) e tomate (Demir \& Ellis, 1992a; Dias et al., 2006a), a máxima qualidade fisiológica geralmente não coincide com o máximo acúmulo de matéria seca. Em espécies de frutos carnosos, como essas, a maturidade fisiológica coincide com a alteração da coloração do exocarpo dos frutos.

Entre os indicadores da maturidade fisiológica, os mais empregados são a coloração de frutos, a capacidade de germinação, o vigor, o grau de umidade, o tamanho e a massa de matéria seca das sementes (Dias et al., 2006a; Vidigal et al., 2011).

O objetivo deste trabalho foi avaliar as alterações fisiológicas durante a ontogênese de sementes das pimentas malagueta e biquinho, e determinar o melhor estádio para colheita.

\section{Material e Métodos}

Foram utilizadas sementes das espécies de pimenta malagueta (Capsicum frutescens L.) e biquinho (Capsicum chinense Jacq.). As sementes foram produzidas em casa de vegetação da Empresa de Pesquisa Agropecuária de Minas Gerais (Epamig), a partir de sementes doadas pela Embrapa Hortaliças.

A semeadura foi realizada em bandejas de isopor com 128 células, contendo substrato comercial utilizado para produção de olerícolas (Plantmax) em casa de vegetação. Os tratos culturais foram realizados conforme recomendações técnicas para a cultura (Pinto et al., 2006).

Pesq. agropec. bras., Brasília, v.48, n.12, p.1546-1554, dez. 2013 DOI: 10.1590/S0100-204X2013001200003 
Quarenta dias após a semeadura em bandejas, quando as plantas apresentavam de três a cinco pares de folhas, realizou-se o transplantio das mudas para vasos de polietileno, com volume de $5 \mathrm{~L}$ de substrato (Plantmax), que foram distribuídos em casa de vegetação previamente limpa. Para garantir a pureza genética das sementes e evitar a ocorrência de polinização cruzada, foram colocados tecidos organza de cor branca ao longo da casa de vegetação, para separar as diferentes espécies.

Durante a fase de florescimento, no dia da antese, as flores foram etiquetadas diariamente, até ser obtido número de sementes suficientes para os testes propostos. Foram coletados frutos de pimenta aos 25, 40, 55, 70, 85 e 100 dias após a antese (DAA) (Figura 1). Após a colheita dos frutos, as sementes foram extraídas manualmente e lavadas em água corrente. Em seguida, foram secadas em condições ambientais, por aproximadamente 24 horas, período de tempo suficiente para remoção da água superficial.

Após a secagem, as sementes foram armazenadas, por no máximo sete dias, a $10^{\circ} \mathrm{C}$. Nas sementes recém extraídas dos frutos, determinou-se o teor de água, a $105 \pm 3^{\circ} \mathrm{C}$, durante 24 horas, tendo-se utilizado quatro subamostras de 50 sementes (Regras para análise de sementes, 2009). A massa da matéria seca das sementes foi determinada junto com seu teor de água (Regras para análise de sementes, 2009).

Para o teste de germinação, foram utilizadas quatro subamostras de 50 sementes, distribuídas sobre duas folhas de papel toalha, umedecidas com solução de $\mathrm{KNO}_{3}$ a $0,2 \%$ equivalente a 2,5 vezes o peso do papel seco, em caixas de plástico do tipo gerbox (Metaquímica Produtos e Análises, Jaraguá do Sul, SC) (Regras para análise de sementes, 2009). As caixas foram mantidas em câmara do tipo BOD, modelo EL 212 (Eletrolab Equipamentos para Laboratório, São Paulo, SP), sob temperatura de $30^{\circ} \mathrm{C}$. As avaliações foram realizadas aos 17 dias após a semeadura, e os resultados foram expressos em percentagem de plântulas normais. A primeira contagem de germinação consistiu do registro da percentagem de plântulas normais obtidas no nono dia após o início do teste de germinação. $O$ índice de velocidade de germinação (IVG) foi determinado a partir de contagens diárias do número de plântulas emergidas até 17 dias após a semeadura (Maguire, 1962).

Para o cálculo de envelhecimento acelerado, 1,0 g de sementes foi distribuído uniformemente sobre bandeja de tela acoplada às caixas de plástico tipo gerbox, contendo, no fundo, $40 \mathrm{~mL}$ de água destilada. As caixas foram tampadas e mantidas em incubadora
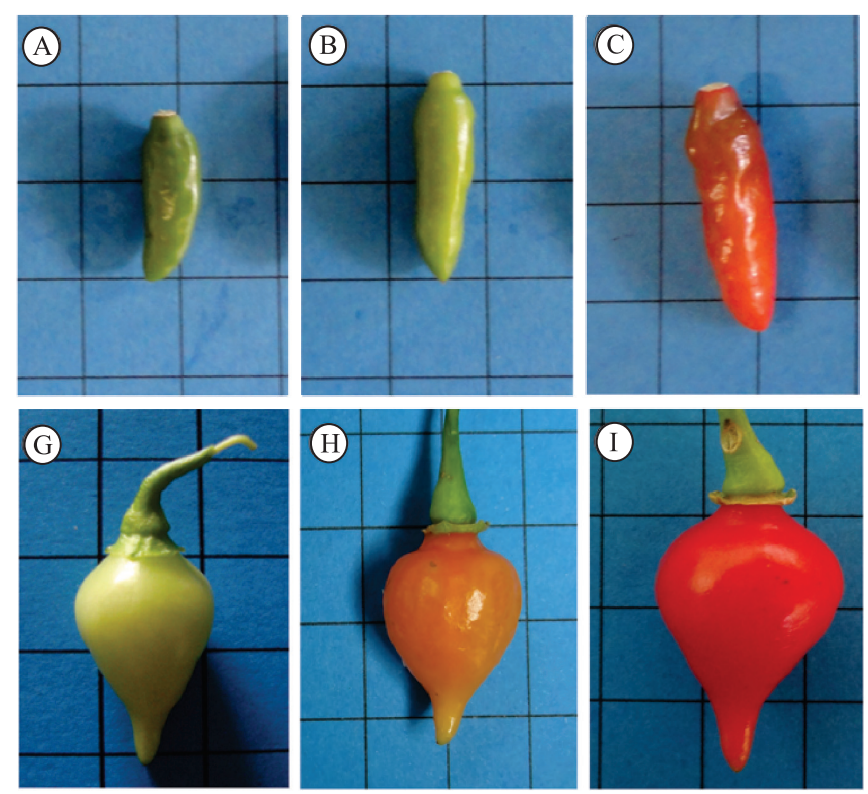
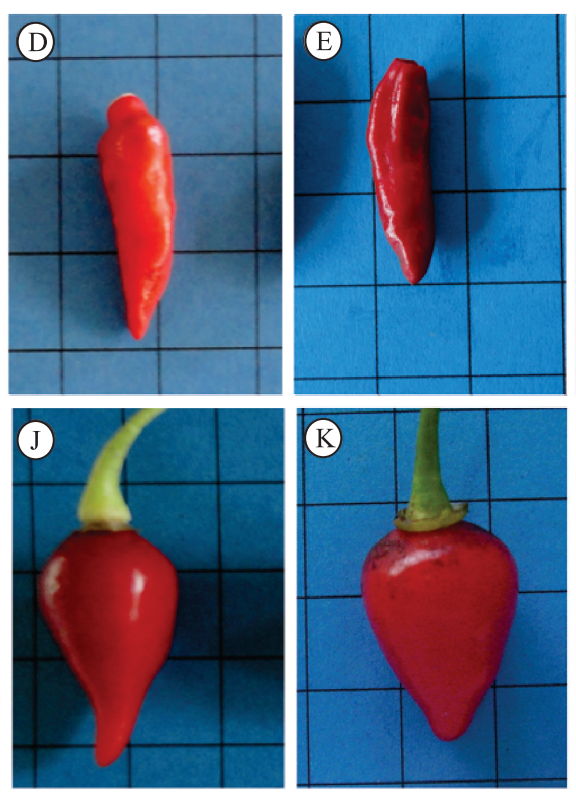
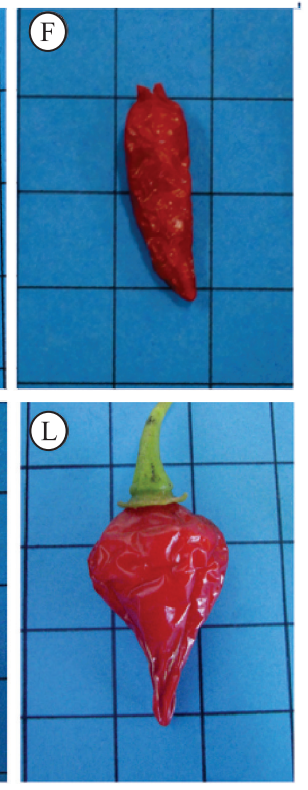

Figura 1. Aspecto visual dos frutos durante o processo de maturação da pimenta malagueta (Capsicum frutescens) - A, 25 dias após a antese (DAA); B, 40 DAA; C, 55 DAA; D, 70 DAA; E, 85 DAA; F, 100 DAA - e da pimenta biquinho (C. chinense) - G, 25 DAA; H, 40 DAA; I, 55 DAA; J, 70 DAA; K, 85 DAA; L, 100 DAA. 
BOD, a $42^{\circ} \mathrm{C}$, por 96 horas (Bhering et al., 2006). Após este período, quatro subamostras de 50 sementes foram submetidas ao teste de germinação, conforme descrito anteriormente. Os resultados foram expressos em percentagem de plântulas normais obtidas no décimo quarto dia após a semeadura.

$\mathrm{O}$ experimento foi realizado em delineamento inteiramente casualizado, com quatro repetições de 50 sementes. Os resultados obtidos foram submetidos à análise de variância, tendo-se utilizado o procedimento Mixed do SAS, versão 9.3 (SAS Institute, Cary, NC, EUA). Os tratamentos (DAA) foram submetidos à decomposição ortogonal em efeitos de primeiro, segundo, terceiro e quarto graus. Ao se observar erro do tipo I, a 5\% de probabilidade, para algum dos efeitos, ajustou-se a equação de regressão com uso da declaração Solution, que é uma função específica do programa SAS, versão 9.3 (SAS Institute, Cary, NC, EUA). Quando houve falta de ajuste significativo para os efeitos acima citados ou comportamento não linear para alguma variável, diferentes funções não lineares foram ajustadas por meio do procedimento NLIN do SAS, versão 9.3 (SAS Institute, Cary, NC, EUA).

A primeira contagem, a germinação e o envelhecimento acelerado foram analisados por meio de modelos lineares generalizados, com o procedimento Glimmix do SAS, versão 9.3 (SAS Institute, Cary, NC, EUA). Assumiu-se distribuição binomial dos dados, tendo-se adotado função de ligação logit.

\section{Resultados e Discussão}

O desenvolvimento das sementes foi caracterizado por acúmulo de matéria seca, que ocorreu até aproximadamente 80 DAA, para pimenta malagueta, quando atingiu $3,19 \mathrm{mg}$ por semente, e até $70 \mathrm{DAA}$, para pimenta biquinho, que atingiu $2,51 \mathrm{mg}$ por semente (Figura 2). De acordo com a definição de Ellis \& Pieta Filho (1992), esses são os pontos de maturidade de massa de cada espécie. Nessa fase do desenvolvimento das sementes, os frutos das duas espécies apresentaram coloração vermelha (Figura 1).

Nas primeiras fases de desenvolvimento das sementes, a massa de matéria seca aumentou rapidamente. Essas fases são caracterizadas pela histodiferenciação, morfogênese e pela síntese e deposição de reservas, como carboidratos, lipídeos e proteínas (Lima et al., 2008; Bewley et al., 2013). $\mathrm{O}$ acúmulo de matéria seca foi mínimo a partir dos 80 , para a malagueta, e dos 70 DAA, para a biquinho, com tendência à estabilização (Figura 2).

Em sementes de pimenta 'Amarela comprida', Vidigal et al. (2011) observaram acréscimos de matéria seca até os 75 DAA. Já Demir \& Ellis (1992b) relataram que a máxima massa de matéria seca de sementes de pimentão é obtida próximo aos 50 DAA, quando de 50 a $60 \%$ dos frutos apresentavam coloração vermelha. Segundo Dias et al. (2006a), o máximo acúmulo de matéria seca de sementes de tomate é obtido aos 75 DAA, fase em que os frutos apresentam $90 \%$ do exocarpo vermelho.
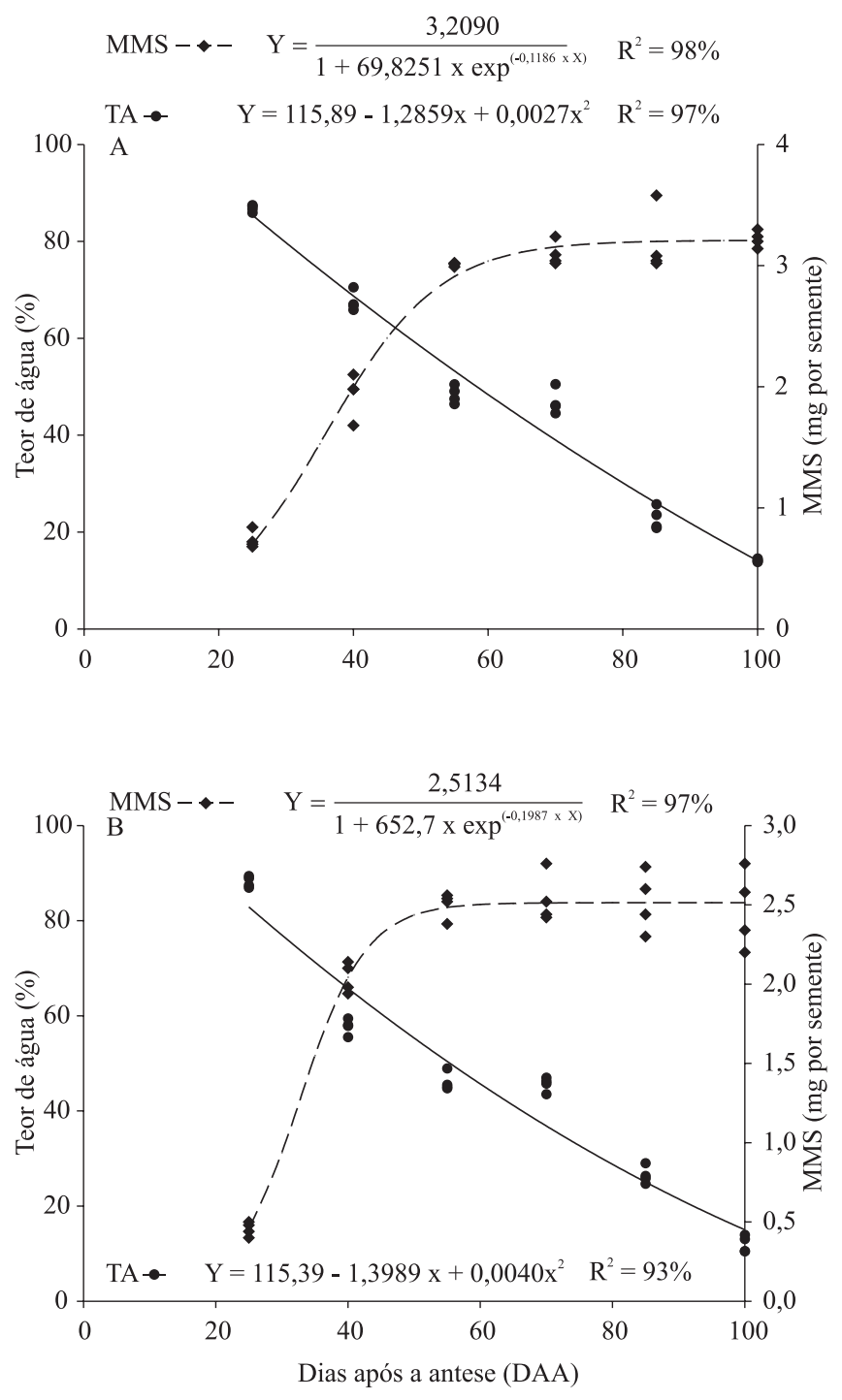

Figura 2. Massa de matéria seca (MMS) e teor de água de sementes colhidas durante o processo de maturação das pimentas: A, malagueta (Capsicum frutescens); e B, biquinho ( $C$. chinense). 
No início do desenvolvimento, aos 25 DAA, as sementes das pimentas malagueta e biquinho apresentaram elevado teor de água, respectivamente de 85 e $82 \%$. O alto teor de água nessa fase de maturação é necessário tanto para a expansão celular quanto para a translocação de metabólitos da planta para as sementes (Bewley et al., 2013). Além disso, o alto teor de água também é fundamental para o posterior acúmulo de reservas, tais como proteínas (Weber et al., 2010), amido (Ingram et al., 2010) e lipídeos (Graham, 2008).

Aos 70 DAA, o teor de água das sementes de malagueta e biquinho foi de aproximadamente 39 e $36 \%$, respectivamente (Figura 2). Para as sementes de pimenta 'Amarela comprida', Vidigal et al. (2011) verificaram que, aos 75 DAA, as sementes apresentavam teor de água de 47,3\%. Queiroz et al. (2011) observaram que sementes de pimenta habanero apresentam teor de água de 56\% aos 67 DAA. Portanto, as sementes das diferentes espécies de pimenta ainda apresentam elevado teor de água nessas épocas de maturação, próximas à maturidade fisiológica.

Em espécies de frutos carnosos, há baixo potencial hídrico no interior dos frutos durante o acúmulo de reservas (solutos osmóticos), o que mantém as sementes com alto teor de água. Porém, esse conteúdo é menor do que o necessário para a germinação das sementes (Welbaum \& Bradford, 1988). Em sementes ortodoxas, como as pimentas, observa-se contínuo decréscimo no teor de água quando elas atingem a máxima matéria seca (Angelovici et al., 2010).

O teor de água das sementes pode não ser considerado bom indicador da sua maturidade fisiológica, uma vez que ele pode ser afetado pelo genótipo e pelas condições ambientais (Vidigal et al., 2011). No entanto, a sua determinação é de extrema importância para a compreensão do processo de maturação.

Durante o desenvolvimento, as sementes adquirem a capacidade de tolerar a desidratação, sem danos irreversíveis. Dessa forma, elas reduzem a atividade metabólica, quando secas, o que pode aumentar sua longevidade, além de conferir tolerância a condições ambientais extremas (Gutierrez et al., 2007; Leprince \& Buitink, 2010). Aos 100 DAA, os valores médios para o teor de água nas sementes foram de 14 e $15 \%$, para as pimentas malagueta e biquinho, respectivamente (Figura 2). A partir desse ponto, o teor de água nas sementes pode variar com alterações na umidade relativa ambiente (Leprince \& Buitink, 2010; Bewley et al., 2013).
A percentagem de germinação das sementes da pimenta malagueta, em função do tempo (DAA), apresentou comportamento cúbico, enquanto que a biquinho, comportamento quadrático (Figura 3). Em ambas as espécies, as sementes colhidas aos 25 e 40 DAA não germinaram. Nesta fase de desenvolvimento, o embrião ainda não tem imaturidade para germinar (Figura 2). Além disso, as sementes ainda estavam acumulando as reservas necessárias para o processo de germinação. O mesmo comportamento

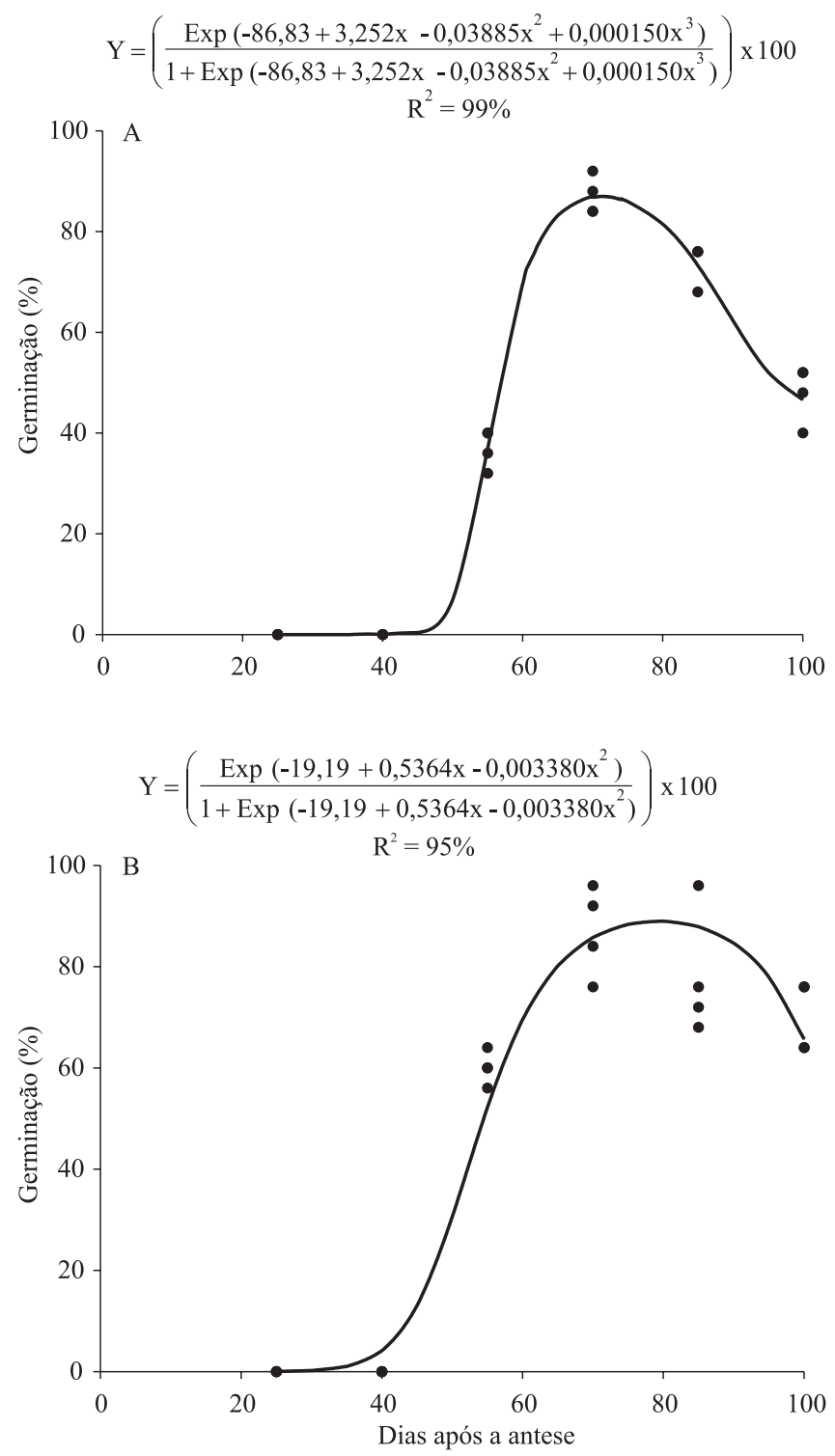

Figura 3. Germinação de sementes colhidas durante o processo de maturação das pimentas: A, malagueta (Capsicum frutescens); e B, biquinho (C. chinense). 
germinativo foi observado por Vidigal et al. (2011), em sementes de pimenta 'Amarela comprida'.

Após os 40 DAA, foram verificados incrementos na percentagem de germinação até aproximadamente 71 DAA, para a pimenta malagueta, e 79 DAA para a pimenta biquinho. Nessas épocas, a percentagem de germinação foi de $86 \%$, para a pimenta malagueta, e de $89 \%$, para a biquinho. Nessa fase de desenvolvimento, embora ainda apresentem elevado teor de água (Figura 2), as sementes adquirem elevado potencial germinativo, principalmente pelo acúmulo de reservas. Em sementes ortodoxas, as sementes continuam a se desenvolver, com a desidratação natural que ocorre na fase final da maturação (Angelovici et al., 2010). As percentagens de germinação das sementes diminuíram a partir dos 71 DAA, para a pimenta malagueta, e dos 79 DAA, para a biquinho. Aos 100 DAA, esses valores foram de 47 e $66 \%$, respectivamente (Figura 3 ).

A permanência dos frutos na planta após a maturidade fisiológica afeta negativamente a qualidade fisiológica das sementes. A pimenta malagueta foi especialmente sensível a esse processo, tendo diminuída sua germinação a valores inferiores a 50\% aos 100 DAA. Portanto, o ideal é que a colheita das sementes da pimenta malagueta seja realizada pelo menos até os $85 \mathrm{DAA}$, quando a percentagem de germinação ainda é superior a $70 \%$. Este percentual é o mínimo recomendado para a comercialização de sementes básicas do gênero Capsicum, de acordo com a portaria 457, de 18 de dezembro de 1986 (Brasil, 1986), e com o projeto de Instrução Normativa de 5 de setembro de 2012 (Brasil, 2012).

A primeira contagem de germinação apresentou comportamento cúbico durante o desenvolvimento das sementes, em ambas as espécies (Figura 4). A primeira contagem de germinação é um teste de vigor simples, realizado simultaneamente ao teste de germinação, e baseia-se no pressuposto de que as sementes mais vigorosas germinam mais rápido. Verificou-se máxima germinação na primeira contagem aos 72 DAA, para a pimenta malagueta, e aos 65 DAA, para a biquinho, com valores de 44 e $60 \%$, respectivamente (Figura 4). A partir dessas épocas, houve decréscimos até os $100 \mathrm{DAA}$, em que foram observadas percentagens de germinação na primeira contagem de $27 \%$, para a pimenta malagueta, e de $17 \%$ para a biquinho.
De acordo com Vidigal et al. (2011), em sementes de pimenta 'Amarela comprida', a primeira contagem de germinação é máxima próximo aos 60 DAA. Os autores relatam ainda que, a partir dessa época, os valores mantêm-se estáveis até os 75 DAA, em torno de $60 \%$.

A pimenta malagueta apresentou aumentos progressivos no IVG com o desenvolvimento das sementes (Figura 5). Aos 55 DAA, observou-se índice de 1,01. Nas demais épocas, os valores foram

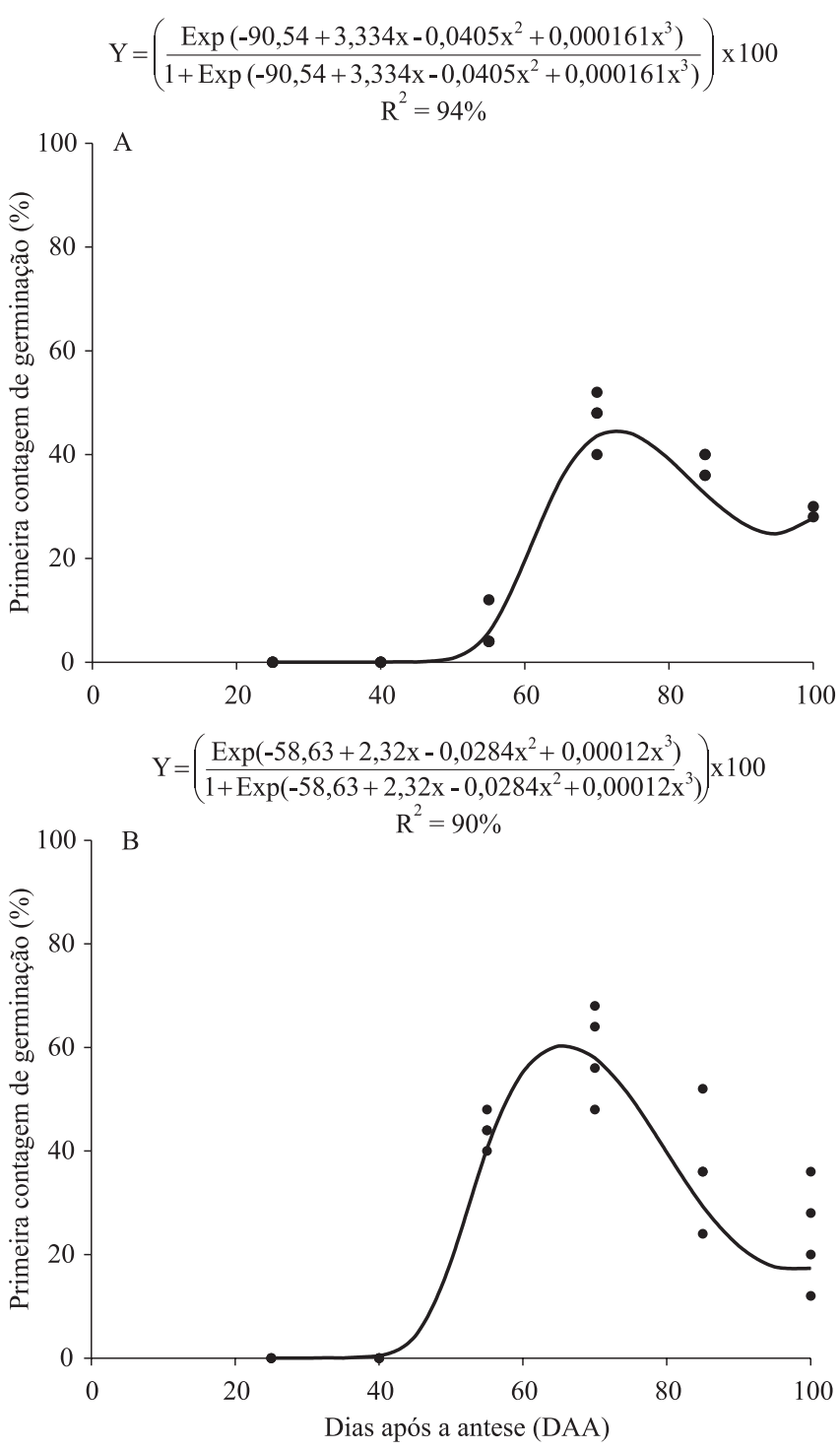

Figura 4. Primeira contagem de germinação de sementes colhidas durante o processo de maturação das pimentas: A, malagueta (Capsicum frutescens); e B, biquinho (C. chinense).

Pesq. agropec. bras., Brasília, v.48, n.12, p.1546-1554, dez. 2013 DOI: 10.1590/S0100-204X2013001200003 
mais expressivos, tendo alcançado IVG de até 3,8 aos 100 DAA. Para a pimenta biquinho, os acréscimos no IVG ocorreram entre 41 e 54 DAA, a uma taxa de 0,2844 ao dia. Aos 41 DAA, observou-se IVG de 0,28; na última época citada, de 3,93; e, a partir dos 55 DAA, em torno de 4,07. Os maiores valores de IVG da pimenta biquinho indicam que essa espécie tem desenvolvimento inicial mais rápido que a pimenta malagueta. Para pimenta 'Amarela comprida', o IVG situa-se entre 2 e 2,5 aproximadamente, aos 60 DAA, e matem-se estável até os 75 DAA (Vidigal et al., 2011).
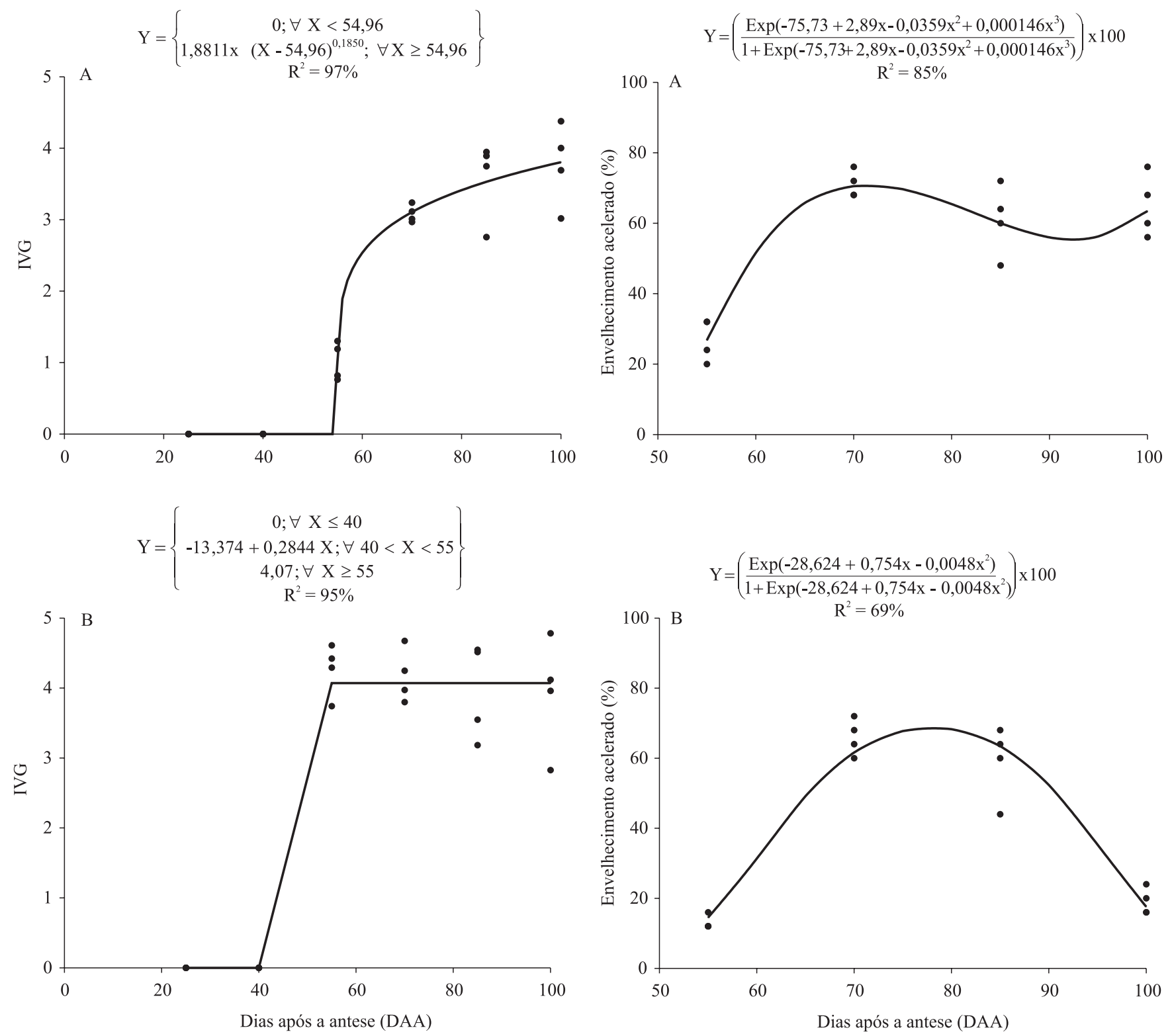

Figura 5. Índice de velocidade de germinação (IVG) de sementes colhidas durante o processo de maturação das pimentas: A, malagueta (Capsicum frutescens); e B, biquinho (C. chinense).

Figura 6. Percentagem de germinação após o teste de envelhecimento acelerado de sementes colhidas durante o processo de maturação das pimentas: A, malagueta (Capsicum frutescens); e B, biquinho (C. chinense). 
O envelhecimento acelerado apresentou comportamento cúbico, para a pimenta malagueta, e quadrático, para a biquinho, durante a maturação das sementes. Dos 55 aos 71 DAA, houve incremento no vigor das sementes da pimenta malagueta, com germinação após o envelhecimento acelerado tendo passado de 27 para $70 \%$. Após os $71 \mathrm{DAA}$, o vigor diminuiu e, aos 100 DAA, a germinação foi de aproximadamente 63\% (Figura 6). Para a pimenta biquinho, dos 55 aos 78 DAA houve acréscimo no vigor, com a germinação após o envelhecimento tendo passado de 14 para $69 \%$. Após os 78 DAA, o vigor das sementes diminuiu e a germinação aos 100 DAA foi de aproximadamente $18 \%$.

O maior vigor das sementes da pimenta malagueta aos 100 DAA, comparada à biquinho, indica que as espécies têm resistências diferentes à condição de estresse imposta durante o teste de envelhecimento acelerado, causada principalmente por altas temperaturas e umidade. Esse estresse pode aumentar a taxa de respiração e o consumo das reservas na semente, o que acelera os processos metabólicos que levam à sua deterioração. Em sementes de pimenta habanero, Queiroz et al. (2011) constataram que o vigor (29\%), avaliado pelo teste de envelhecimento acelerado, foi maior para as sementes colhidas aos $67 \mathrm{DAA}$, e que as sementes colhidas aos 50 e 60 DAA apresentaram vigor praticamente nulo. Para sementes de pimenta 'Amarela comprida' a germinação manteve-se em torno de $80 \%$, dos 55 até os 75 DAA (Vidigal et al., 2011). $\mathrm{O}$ vigor das sementes de pimenta malagueta foi similar ao relatado para o pimenta 'Amarela comprida' (Vidigal et al., 2011), enquanto a pimenta biquinho mostrou vigor semelhante ao relatado por Queiroz et al. (2011), para pimenta habanero.

Em geral, pelos testes de germinação e de vigor utilizados, observou-se que houve acréscimos até aproximadamente os 70 DAA, e que, a partir desta época de maturação, as sementes tornaram-se menos vigorosas.

A máxima qualidade fisiológica pode ser determinada a partir da combinação de características relacionadas ao potencial germinativo e ao vigor das sementes. A máxima qualidade fisiológica, obtida neste trabalho em sementes colhidas em torno dos 70 DAA, está de acordo com a hipótese de que ela é atingida próximo ao final do período de acúmulo de matéria seca, conforme Welbaum \& Bradford (1988) e Demir et al. (2004).

\section{Conclusão}

A maturidade fisiológica de sementes das pimentas malagueta e biquinho ocorre em torno dos 70 dias após a antese, época ideal para colheita.

\section{Agradecimentos}

À Coordenação de Aperfeiçoamento de Pessoal de Nível Superior (Capes), ao Conselho Nacional de Desenvolvimento Científico e Tecnológico (CNPq), à Fundação de Amparo à Pesquisa do Estado de Minas Gerais (Fapemig), pelo apoio financeiro, e à Embrapa Hortaliças pelo fornecimento das sementes.

\section{Referências}

ANGELOVICI, R.; GALILI, G.; FERNIE, A.R.; FAIT, A. Seed desiccation: a bridge between maturation and germination. Trends in Plant Science, v.15, p.211-218, 2010. DOI: 10.1016/j. tplants.2010.01.003.

BERGER, F.; HAMAMURA, Y.; INGOUFF, M.; HIGASHIYAMA, T. Double fertilization - caught in the act. Trends in Plant Science, v.13, p.437-443, 2008. DOI: 10.1016/j. tplants.2008.05.011.

BEWLEY, J.D.; BRADFORD, K.J.; HILHORST, H.W.M.; NONOGAKI, H. Seeds: physiology of development, germination and dormancy. $3^{\text {rd }}$ ed. New York: Springer, 2013. 392p. DOI: 10.1007/978-1-4614-4693-4.

BHERING, M.C.; DIAS, D.C.F. dos S.; VIDIGAL, D. de S.; NAVEIRA, D. dos S.P. Teste de envelhecimento acelerado em sementes de pimenta. Revista Brasileira de Sementes, v.28, p.64-71, 2006. DOI: 10.1590/S0101-31222006000300010.

BRASIL. Ministério da Agricultura. Portaria no 457, de 18 de dezembro de 1986. Estabelece para todo o território nacional, procedimentos e padrões de sementes olerícolas, para distribuição, transporte, e comércio de sementes fiscalizadas, e para importação. Diário Oficial [da] República Federativa do Brasil, 23 dez. 1986. Seção 1, p.19653.

BRASIL. Ministério da Agricultura, Pecuária e Abastecimento. Portaria $n^{\circ} 111$, de 4 de setembro de 2012. Estabelece os padrões de identidade e qualidade para a produção e a comercialização de sementes de espécies olerícolas, condimentares, medicinais e aromáticas, disposto em anexo. Diário Oficial [da] República Federativa do Brasil, 5 set. 2012. Seção 1, p.3-4.

CASTRO, R.D.; BRADFORD, K.J.; HILHORST, H.W.M. Desenvolvimento de sementes e conteúdo de água. In: FERREIRA, A.G.; BORGUETTI, F. Germinação: do básico ao aplicado. Porto Alegre: Artmed, 2004. p.51-67.

DEMIR, I.; ELLIS, R.H. Changes in seed quality during seed development and maturation in tomato. Seed Science Research, v.2, p.81-87, 1992a. DOI: 10.1017/S0960258500001173.

Pesq. agropec. bras., Brasília, v.48, n.12, p.1546-1554, dez. 2013 DOI: $10.1590 / \mathrm{S} 0100-204 X 2013001200003$ 
DEMIR, I.; ELLIS, R.H. Development of pepper (Capsicum annuиm) seed quality. Annals of Applied Biology, v.121, p.385-399, 1992b. DOI: 10.1111/j.1744-7348.1992.tb03452.x.

DEMIR, I.; MAVI, K.; OZTOKAT, C. Changes in germination and potential longevity of watermelon (Citrullus lanatus) seeds during development. New Zealand Journal of Crop and Horticultural Science, v.32, p.139-145, 2004. DOI: 10.1080/01140671.2004.9514288.

DIAS, D.C.F.S.; RIBEIRO, F.P.; DIAS, L.A.S.; SILVA, D.J.H.; VIDIGAL, D.S. Tomato seed quality harvested from different trusses. Seed Science and Technology, v.34, p.681-689, $2006 \mathrm{~b}$.

DIAS, D.C.F.S.; RIBEIRO, F.P.; DIAS, L.A.S.; SILVA, D.J.H.; VIDIGAL, D.S. Tomato seed quality in relation to fruit maturation and post-harvest storage. Seed Science and Technology, v.34, p.691-699, 2006a.

ELLIS, R.H.; PIETA FILHO, C. Seed development and cereal seed longevity. Seed Science Research, v.2, p.9-15, 1992.

GRAHAM, I.A. Seed storage oil mobilization. Annual Review of Plant Biology, v.59, p.115-142, 2008. DOI: 10.1146/annurev. arplant.59.032607.092938.

GUTIERREZ, L.; VAN WUYTSWINKEL, O.; CASTELAIN, M.; BELLINI, C. Combined networks regulating seed maturation. Trends in Plant Science, v.12, p.294-300, 2007. DOI: 10.1016/j. tplants.2007.06.003.

HEHENBERGER, E.; KRADOLFER, D.; KÖHLER, C. Endosperm cellularization defines an important developmental transition for embryo development. Development, v.139, p.2031-2039, 2012. DOI: 10.1242/dev.077057.

INGRAM, G.C. Family life at close quarters: communication and constraint in angiosperm seed development. Protoplasma, v.247, p.195-214, 2010. DOI: 10.1007/s00709-010-0184-y.

KESAVAN, M.; SONG, J.T.; SEO, H.S. Seed size: a priority trait in cereal crops. Physiologia Plantarum, v.147, p.113-120, 2013. DOI: 10.1111/j.1399-3054.2012.01664.x.

LEPRINCE, O.; BUITINK, J. Desiccation tolerance: from genomics to the field. Plant Science, v.179, p.554-564, 2010. DOI: 10.1016/j.plantsci.2010.02.011.

LIMA, R.B.S.; GONÇALVES, J.F. de C.; PANDO, S.C.; FERNANDES, A.V.; SANTOS, A.L.W. dos. Primary metabolite mobilization during germination in rosewood (Aniba rosaeodora Ducke) seeds. Revista Árvore, v.32, p.19-25, 2008. DOI: 10.1590/ S0100-67622008000100003.

MAGUIRE, J.D. Speeds of germination-aid in selection and evaluation for seedling emergence and vigor. Crop Science, v.2, p.176-177, 1962. DOI: 10.2135/cropsci1962.0011183X00020002 $0033 x$.
MARTINS, D.C.; VILELA, F.K.J.; GUIMARÃES, R.M.; GOMES, L.A.A.; SILVA, P.A. Physiological maturity of eggplant seeds. Revista Brasileira de Sementes, v.34, p.534-540, 2012. DOI: 10.1590/S0101-31222012000400002.

PINTO, C.M.F.; PUIATTI, M.; CALIMAN, F.R.B.; MOREIRA, G.R.; MATTOS, R.N. Clima, época de semeadura, produção de mudas, plantio e espaçamento na cultura da pimenta. Informe Agropecuário, v.27, p.40-49, 2006.

QUEIROZ, L.A.F.; VON PINHO, E.V. de R.; OLIVEIRA, J.A.; FERREIRA, V. de F.; CARVALHO, B.O.; BUENO, A.C.R. Época de colheita e secagem na qualidade de sementes de pimenta habanero yellow. Revista Brasileira de Sementes, v.33, p.472-481, 2011. DOI: 10.1590/S0101-31222011000300010.

REGRAS para análise de sementes. Brasília: Ministério da Agricultura, Pecuária e Abastecimento, 2009. 399p.

TOKUHISA, D.; DIAS, D.C.F. dos S.; ALVARENGA, E.M.; DIAS, L.A. dos S.; MARIN, S.L.D. Época de colheita dos frutos e ocorrência de dormência em sementes de mamão (Carica papaya L.). Revista Brasileira de Sementes, v.30, p.75-80, 2008. DOI: 10.1590/S0101-31222008000200010.

VIDIGAL, D. de S.; DIAS, D.C.F. dos S.; DIAS, L.A. dos S.; FINGER, F.L. Changes in seed quality during fruit maturation of sweet pepper. Scientia Agricola, v.68, p.535-539, 2011. DOI: 10.1590/S0103-90162011000500004.

VIDIGAL, D. de S.; DIAS, D.C.F. dos S.; NAVEIRA, D. dos S.P.C.; ROCHA, F.B.; BHERING, M.C. Qualidade fisiológica de sementes de tomate em função da idade e do armazenamento pós-colheita dos frutos. Revista Brasileira de Sementes, v.28, p.87-93, 2006. DOI: 10.1590/S0101-31222006000300013.

VIDIGAL, D. de S.; DIAS, D.C.F.S.; VON PINHO, E.V. de R.; DIAS, L.A. dos S. Alterações fisiológicas e enzimáticas durante a maturação de sementes de pimenta (Capsicum annuum L.). Revista Brasileira de Sementes, v.31, p.129-136, 2009a. DOI: 10.1590/S0101-31222009000200015.

VIDIGAL, D.S.; DIAS, D.C.F.S.; VON PINHO, E.R.V.; DIAS, L.A.S. Sweet pepper seed quality and Lea-protein activity in relation to fruit maturation and post-harvest storage. Seed Science and Technology, v.37, p.192-201, 2009b.

WEBER, H.; SREENIVASULU, N.; WESCHKE, W. Molecular physiology of seed maturation and seed storage protein biosynthesis. Plant Developmental Biology, v.2, p.83-104, 2010.

WELBAUM, G.E.; BRADFORD, K.J. Water relations of seed development and germination in muskmelon (Cucumis melo L.) I. Water relations of seeds and fruit development. Plant Physiology, v.86, p.406-411, 1988. DOI: 10.1104/pp.86.2.406.

Recebido em 4 de outubro de 2013 e aprovado em 26 de novembro de 2013 